Discussion This realist review revealed that effective RPs depend largely on strong intersectoral actions involving leadership shared among healthcare, workplace and insurance stakeholders. These findings confirm the complex nature of program implementation.

\section{LEGAL AND POLICY PROVISIONS FOR REASONABLE ACCOMMODATION IN EMPLOYMENT OF PERSONS WITH MENTAL DISABILITY IN EAST AFRICA: A REVIEW}

${ }^{1}$ ID Ebuenyi*, ${ }^{2} \mathrm{M}$ Nthenge, ${ }^{1} \mathrm{~B}$ Regeer, ${ }^{1} \mathrm{~J}$ Bunders. 'Athena Institute, Faculty of Sciences, Vrije Universiteit Amsterdam, The Netherlands; ${ }^{2}$ Independent Consultant on disability rights, gender and youth issues, Kenya

\subsection{6/oemed-2018-ICOHabstracts.1568}

Introduction Globally, legal and policy provisions recommends reasonable accommodation for persons with disability. These provisions are endorsed by international human rights policy provisions and the country specific disability and mental health legislations. However, persons with mental disability continue to face significant limitations to employment in East Africa. Imprecise definitions of mental disability and reasonable accommodation have been blamed for non-implementation of the policy and legal provisions.

Methods The disability laws, human rights legislations and mental health laws of 18 East African countries were reviewed using the WHO MiNDbank and in relation to article 27 of the United Nations Convention on Rights for persons with disabilities(CRPD).

Results We found that although $14(78 \%)$ of the countries have ratified the CRPD only $12(67 \%)$ have explicit definition of mental illness as a disability. Only 11 (62\%) have explicit laws mandating employers to provide reasonable accommodation for persons with mental disability. It is unclear whether the policy and legal provisions perceive reasonable accommodation as a progressive or immediate obligation of the countries.

Discussion The UN CRPD defines persons with disabilities to include those who have long-term physical, mental, intellectual or sensory impairments, which in interaction with various barriers may hinder their full and effective participation in society on equal basis with others Both the CRPD and Sustainable Development(SDG) Goals recommends inclusive employment for persons with all forms of disabilities. In spite of the availability of these legislations, opportunities of employment for persons with mental disabilities remain dismal on account of cultural and social stereotypes about mental illness in addition to absence of actionable points in policies and legislations. There is lack of clear and specific definition of reasonable accommodation in the examined laws and concerted action by all state parties is required for improved employment for persons with mental disability.

\section{RETROSPECTIVE STUDY OF THE PROFILE OF DISABLED EX-WORKERS APPLYING FOR THE DISABILITY PENSION OF THE BRAZILIAN NATIONAL SOCIAL SECURITY INSTITUTE}

LR Ferreira, VASB Capeli, RL Fregonesi, AFA Lemos, CM Galhardi. UNIFAE Medical School, São João da Boa Vista-SP, Brazil

10.1136/oemed-2018-ICOHabstracts. 1569
Introduction The assessment of the disabled person can be carried out through the application of various instruments, such as the International Classification of Functioning, Disability and Health (ICF). It has been used by INSS since 2011 for the concession of disability pension (DP) benefit. Since its implementation as an evaluation instrument, little is known about the results of ICF application and the applicant`s profile. For this reason, it is important to retrospectively analyse the profile of the individuals that require this benefit, in relation to gender, age, educational level and previous main occupation.

Methods A retrospective study was carried out involving the evaluation of 173 DP applicants from the Brazilian National Social Security Institute (INSS) from March 2016 until December 2016 and it was collected the following data: gender, age, educational level, marital status, International Classification of Diseases (ICD10) and previous main occupation. The data were divided according to the main prevalent categories.

Results It was demonstrated that most applicants were female, single, with complete primary education and average age of 43 years-old, with the most frequent distribution of requests occurred between 55 and 59 years-old, the most of them were agricultural wokers (42\%). In regard to ICD-10 classification, the most common disorders were: psychiatric $(25,52 \%)$ followed by neurological/muscle (15,90\%), cardiovascular $(10,46 \%)$ and trauma/sequelae $(8,36 \%)$ diseases.

Discussion It was concluded that most applicants for the DP benefits were agricultural female workers with low education presenting mainly with psychiatric, neurological, cardiologic and trauma diseases. The use of the ICF as an instrument can contribute to the real living conditions of people with disabilities being included in the statistics, allowing actions and decisions to be guided, policies and interventions defined and budgets allocated.

\section{EVALUATION OF THE INTERNATIONAL CLASSIFICATION OF FUNCTIONING, DISABILITY AND HEALTH FOR ASSESSING DISABILITY OF THE BRAZILIAN NATIONAL SOCIAL SECURITY INSTITUTE}

LR Ferreira*, VASB Capeli, RL Fregonesi, AFA Lemos, CM Galhardi. UNIFAE Medical School, São João da Boa Vista-SP, Brazil

\subsection{6/oemed-2018-ICOHabstracts. 1570}

Introduction The assessment of the person with disabilities can be made by using the ICF (International Classification of Functioning, Disability and Health). It has been used by the Brazilian National Social Security Institute (INSS) to concede the Social Security Continuous Benefit (BPC) for disabled person, and it evaluates incapacity for work and independent life. This study analysed the results of the ICF used by the social security medical examiners and social workers on the evaluation of disabled person.

Methods This was a retrospective study involving the evaluation of 173 BPC applicants of the INSS in Brazil from March to December 2016 and collected the following data: average scores from 0 to 4 (0-no disability, 1-mild, 2-moderate, 3severe, 4-complete disability) for these ICF domains: environmental factors and activities/participation made by the social worker, body functions and activities/participation made by the medical examiners and the final results for granting or not the benefit. It was applied the statistical test of Kruskal-Wallis, the post test of Dunn $(\mathrm{p}<0.05)$. 